\title{
Contribution of Life Cycle Knowledge towards Environmental Performance of ISO 14001 Certified Malaysian Companies: Analysis of ISO 14001 and Selected Life Cycle Management Tools
}

\author{
Natasha Ashvinee Rajendran*, Quiena Lia Anak Jimi and Amir Hamzah Sharaai \\ Department of Environment, Faculty of Forestry and Environment, Universiti Putra Malaysia, 43400 Serdang, \\ Selangor, Malaysia
}

\begin{abstract}
The ability to enhance environmental performance has emerged as a pivotal corporate strategy for businesses in Malaysia. While the ISO 14001:2015 has been promoted extensively by the Malaysian Department of Standards, its adoption remains low and at a slow pace. There is scarce research to demonstrate the linkage between environmental knowledge, the implementation of life cycle management tools and environmental performance. Therefore, the first aim of this study is to assess the different knowledge levels of respondents on ISO 14001:2015 and four assessment methodologies (i.e., Life Cycle Assessment, Carbon Footprint, Water Footprint, and Material Flow Cycle Accounting). The second aim is to determine whether these knowledge bases contribute to the firms' environmental performance. A total of 157 ISO-certified firm owners responded to the self-administered questionnaires. A One-Way ANOVA test revealed a difference in knowledge levels, with Life Cycle Assessment having the highest score and Material Flow Cycle Accounting having the lowest. Multiple regression revealed ISO 14001, Material Flow Cycle Accounting, and Carbon Footprint knowledge to contribute to environmental performance significantly. Counterintuitively, Life Cycle Assessment and Water Footprint exerted no significance on environmental performance. Policy implications include

ARTICLE INFO

Article history:

Received: 11 November 2019

Accepted: 20 July 2020

Published: 12 November 2021

DOI: https://doi.org/10.47836/pjssh.29.4.05

E-mail addresses:

natasharajendran10@gmail.com (Natasha Ashvinee Rajendran) quienalia1995@yahoo.com (Quiena Lia Anak Jimi)

amirsharaai@upm.edu.my (Amir Hamzah Sharaai)

* Corresponding author information dissemination and training by governmental officials for firm owners and exposure to life cycle management tools.

Keywords: Carbon footprint, environmental performance, green innovation, industrial ecology, life cycle thinking, life cycle assessment, water footprint
\end{abstract}




\section{INTRODUCTION}

Today's business responsibility entails incorporating sustainability within its production domain (Abdullah et al., 2017; Suryanto et al., 2018). While trade-offs are common in pursuing the sustainability agenda, a discussion on introducing synergy into the business arena is considered worth the extra effort. A rising consensus can be seen after which socioeconomic outputs and environmental welfare are jointly increased. A new paradigmatic shift that expands the Triple Bottom Line (TBL) (i.e., profit, planet, and people) positively (Svensson et al., 2018) is necessary, hence requiring businesses to implement a new program or tool in their production.

The ISO 14001 standard is now a ubiquitous benchmark for organizations wishing to communicate with stakeholders regarding their environmental accountability (Boiral et al., 2018; Ejdys et al., 2016; Murmura et al., 2018). However, despite its prolific popularity, arguments have arisen among academicians and non-academicians alike: the standard perceives sustainability through considering environmental impacts only via product distribution, simultaneously ignoring end-of-product life cycles (Pfister et al., 2017). Following the increased awareness for smart development, the standard underwent revision in 2015 in which a significant modulation involved the incorporation of Life Cycle Thinking (Ingrao et al., 2018; International Organization for Standardization, 2017; Lee et al., 2017). Life Cycle Thinking is an approach to evaluate the tangible environmental impacts of production activities and a medium to understand and visualize a broader sense of both upstream and downstream decision impacts (Fernando \& Sathasivam, 2017; Testa et al., 2016; Turner et al., 2016).

The potential to streamline life cycle activities in conjunction with an adaptable holistic inventory of economic, environmental, and social impacts is highly advantageous to its adopters (Pawel et al., 2016; Rieckhof \& Guenther, 2018). It provides users with a systematic assessment of existing issues that may not have been recognized earlier. Other benefits include delineation of specific roles among different stakeholders, the input of data required by different stakeholders, and thorough cost-benefit decision analysis (Ridoutt et al., 2016; Weidema et al., 2018). The latter is possible by working with quantitative inventory tools inputs, namely Carbon Footprint, Life Cycle Assessment, Material Flow Cost Accounting, and Water Footprint (Giannarakis et al., 2017; Lee et al., 2016; Pfister et al., 2017).

Despite extensive promotion being made by Malaysian environmental advocates, the adoption of ISO 14001 remains low and at a slow pace. Both governmental authorities and businesses were found to be still utilizing the ISO 14001:2004, either unaware or ignoring the update to its more sophisticated successor, the ISO 14001:2015 (Nero et al., 2016). Moreover, the recognition and influence of Life Cycle Thinking and Life Cycle Analysis have been marginal among businesses in Malaysia. It can be postulated that the contributing factor to this phenomenon is the knowledge and consciousness levels of the standard users. 
To our knowledge, the paucity of studies relating to ISO 14001 knowledge, adoption rates by businesses, and environmental performance are present both across the local and international domains. A similar phenomenon can also be observed about research on Life Cycle Thinking and Life Cycle Management tools. Moreover, the availability and credibility of the existing literature on environmental awareness and its impact on environmental performance differ substantially across regions and case studies. The varying information prevents its general utilization and applicability to user behavior. The literature also lacks comparative studies on knowledge levels of companies about different environmental management tools and certification systems.

Hence, the aim of this study is two-fold in nature. Firstly, we aim to explore the knowledge levels of ISO 14001 certified firm personnel. Their knowledge levels will be assessed via a survey where they will be tested based on ISO 14001 and Life Cycle Management tool guidelines. The second aim is to measure the significance of different knowledge bases on firm environmental performance. It will be analyzed through multiple regression techniques. The cognizance of qualitatively different levels in which firm owners understand ISO 14001 and Life Cycle Management inventory tools will help to reveal a new focal awareness of the different dimensions of environmental management standards. Hence, relevant stakeholders will discern the critical information aspects that require evaluation for further improvement and dissemination.

\section{LITERATURE REVIEW}

\section{Phases of Life Cycle Assessment and Life Cycle Management Tools}

While the definition of environmental performance varies across studies, content assessment places it in two distinct categories. The first one deals with performance as operational performance indicators, such as input use, water emission, consumption, and waste generation (Jolliet et al., 2018; Kjaer et al., 2018). Even though these indicators successfully capture short-term changes, long-term ones such as stakeholder benefits are ignored. In a nutshell, operational performance indicators deal with quantitative methodologies (i.e., numerical indicators). Meanwhile, the second category views performance in a broader scope in which benefits are perceived without the assistance of numerical data. The indicators include standard compliance augmentation, waste reduction, economic savings, systemization of production operations, and competitive advantage amongst competitors (Marota et al., 2017; Rieckhof \& Guenther, 2018). These qualitative data are richer in scope and unrestricted to performance based on mere rigorous indicators.

\section{ISO 14001}

Although the IS0 14001 standard does not recommend a universal corporate method for mitigating adverse environmental impacts, it does obligate businesses to consider resources in both past and current production activities (Fernando \& Sathasivam, 2017; Murmur et al., 2018; Turner et al., 2016). In 2015, the ISO 14001:2004 underwent 
a rather elaborate revision and emerged with ten clauses instead of four previously and 16 mandatory guidelines instead of 12. A key difference lies in the newly incorporated Life Cycle Thinking (Fonseca \& Domingues, 2018; Pfister et al., 2017). Succinctly, this perspective involves the organizations' control and influence on how their products are designed, manufactured, distributed, and consumed to ameliorate negative environmental impacts at any stage within the life cycle (Chatzisymeon et al., 2017; Pawel et al., 2016; Testa et al., 2016). Previously, it was not mandated for businesses to peruse and consider their production impact on the environment. Another major change is the evaluation specificity on the firm's environmental performance. All evaluations will from herewith necessitate quantitative data and periodic monitoring (Oliveira et al., 2016).

These key amendments in the ISO standard emphasize the use of Life Cycle Thinking to prevent adverse impacts from being shifted unintentionally outside the product life cycle (Ridoutt et al., 2016; H. K. Salim et al., 2018). Furthermore, life Cycle Thinking necessitates businesses to expand their monitoring to both raw material suppliers (up the chain) and customers (down the chain), to evaluate their environmental impact, if any (Daddi et al., 2017; Jolliet et al., 2018; Weidema et al., 2018). With this additional information, businesses are accountable for addressing these impacts via the utilization of environmental management tools and/or systems, like those discussed below.

\section{Life Cycle Assessment}

Under the banner of Life Cycle Management is Life Cycle Assessment, which evaluates the environmental triggers and potential impacts of a product system throughout its life cycle stages; from raw input acquirement to manufacturing and distribution, and finally, end-of-life treatment (Kjaer et al., 2018; Pawel et al., 2016; Ridoutt et al., 2016). Life Cycle Assessment, a nonmonetary instrument, aims at portraying environmental impacts that are impossible to internalize in a monetary form (Ridoutt et al., 2016). The phrase "life cycle" defines the interlinked, continuous stages of a product system, from the extraction of raw material to the final disposal (Pawel et al., 2016).

In the second phase, the life cycle inventory evaluates and quantifies resource inputs and outputs (Rieckhof \& Guenther, 2018). Again, two kinds of data are required, namely a) natural resource inputs and b) techno-sphere materials, e.g., fuel, electricity, and heat energy. In this study, only two forms of inventoried data (Carbon Footprint and Water Footprint) were reviewed based on its review popularity among academicians.

\section{Carbon Footprint}

Carbon Footprint gives insights on climate change via greenhouse gas emissions (Giama \& Papadopoulos, 2018; Giannarakis et al., 2017). It measures carbon emissions that are directly or indirectly generated by manufacturing activities accumulated over a product's life span (Carvalho et al., 2016). While there appear to be significant 
differences among footprint calculations, the carbon dioxide equivalent ( $\left.\mathrm{CO}_{2}-\mathrm{e}\right)$ mass established in the 100-year Global Warming Potential (set as 1) has been ubiquitously received as the mandatory reporting unit for footprint analysis (Fernando \& Hor, 2017; Giannarakis et al., 2017). Emissions of carbon, methane, and sulfur dioxide emitted through fossil fuel combustion, manufacturing, distribution, and site clearance are converted into carbon dioxide equivalents.

The evaluation mentioned above is primarily tailored to monitor and calculate greenhouse gas emissions throughout the entire supply chain (Carvalho et al., 2016; Giama \& Papadopoulos, 2018). In addition, periodic appraisals are aimed at identifying ways to decrease emissions.

\section{Water Footprint}

Water Footprint is another mono-criterion tool that deals with water usage and discharge, including ignition and run-off (Pfister et al., 2017). It involves direct water consumption released by industries and indirect water usage associated with manufacturing along the supply chain stages (Aivazidou et al., 2016; Hoekstra, 2017). Technically, Water Footprint is the volume of direct and/or indirect freshwater used in producing a particular product that is also measured at the point of production in the supply chain (Lee et al., 2016; Safie et al., 2018).

Under the banner of Life Cycle Analysis, there are two types of impact assessment linked to this tool: midpoint indicator that describes a potential impression in the center of the cause-effect link, i.e., water deficiency and endpoint indicator that delineates potential damage transpiring at the end of the cause-effect link (e.g., river ecosystem scarcity due to factory usage) (Aivazidou et al., 2016; Hoekstra, 2017). This assessment involves numerous indicators for evaluation, but data is reportedly more tangible and allows a systematic collection and comparison of varying environmental occurrences (e.g., consumption, pollution).

Material Flow Cost Accounting. Material Flow Cost Accounting is primarily recognized as a tool to reduce material loss and positively impact economic and environmental performance. It aims at mitigating both impacts and waste cost simultaneously; thus, increasing financial efficiency (K. M. Salim et al., 2018; Turner et al., 2016). It is primarily an accounting tool that quantifies input flow in physical and fiscal components (K. M. Salim et al., 2018). It is centered on an input-output examination of material flows. A relatively new life cycle thinking approach is designed to implicitly recognize material and energy flows in business operations (El-Mousawi \& Charbaji, 2016; Marota et al., 2017). An extra feature is the production performance evaluation index. It is essential as it provides ample physical and numerical data on the value of poor-quality products, i.e., negative output and disposal cost (Rieckhof \& Gunther, 2018; Turner et al., 2016).

The merging of Material Flow Cost Accounting with previously mentioned 
assessment tools is favorable based on two rationales. First, all these approaches are built on similar constructs of material flow and, therefore complementary (Turner et al., 2016). The premise of the Life Cycle Assessment is built upon the ability to identify resource consumption hotspots and related impacts (Marota et al., 2017). Similarly, Material Flow Cost Accounting aids in visualizing material flows of limited inputs and monetizing resource inefficiencies (K. M. Salim et al., 2018; Marota et al., 2017). From an economic standpoint, the reduced negative output will decrease the cost of the finished product. It, in turn, generates positive impacts, namely higher customer satisfaction and an increased market share amongst competitors (Turner et al., 2016). Concisely, the broader dissemination of Material Flow Cost Accounting amongst Malaysian companies is beneficial as the tool improves a firm's environmental performance via efficient resource utilization and allocation (K. M. Salim et al., 2018).

Together, these approaches successfully determine hypothetical incompetence and potential refinements (Jolliet et al., 2018). All approaches provide a common denominator for assessment by different individuals with varying focus points, e.g., engineers and environmental officials (Pawel et al., 2016). Jointly, these approaches generate a thorough feedback process involving improvement approaches and investment measures (Daddi et al., 2017; Jolliet et al., 2018). Feedback in the form of environmental indicators assists in increasing awareness amongst stakeholders via sustainability reporting (Fernando \& Sathasivam, 2017).

\section{Relationship between Knowledge and} Intent to Adopt Sustainable Tools. The theory of knowledge and awareness by Marton and Booth (1997) is relevant for this study as it examines learning outcomes from the focal viewpoint of industry owners to ISO 14001, Life Cycle Management, and its tools. Knowledge acquisition is a constituent that occurs in the human automatic approach (Sammalisto et al., 2016). The acquisition may occur either consciously or through a series of unconscious actions. The awareness precedes the control, modification, and subsequent change in behavioral decisions (Ahmad et al., 2016; Mei et al., 2016). Thus, purposeful, active behavior, i.e., adoption of ISO 14001, is materialized via knowledge procurement. Two types of knowledge are relevant to this study: system knowledge, i.e., awareness of how a system or process operates (ISO 14001 and Life Cycle Thinking), and effective knowledge, i.e., characteristics and benefits of a process or behavior. Each form possesses a pivotal influence in decision-making (Anđić \& Vorkapić, 2017).

Having high environmental awareness is not necessarily stimulated by proenvironmental behavior; in fact, it may precede it (Marton \& Booth, 1997; Mei et al., 2016). Another scenario is that an environmentally aware individual may not necessarily prescribe pro-environmental behavior (Ahmad et al., 2016). In this 
research context, measuring environmental awareness is related to the firm owner's understanding of the mandatory guidelines of ISO 14001 and the four Life Cycle Management tools.

The three levels of awareness utilized to generate behavioral change: 1) perception in which the characteristics and dynamics of the relevant element(s) are visually perceived, 2) understanding in which the information processes from the first level are upgraded to comprehend the element's significance in alignment with pertinent objectives or mission, 3) projection where the potential to project any decision made soon exist (Anđić \& Vorkapić, 2017).

\section{METHODS}

Prior to data collection, interviews were conducted with a panel of experts on ISO 14001 standard and Life Cycle Management tools, i.e., lecturers, Malaysian Department of Standards officer, Health and Safety executives from the private sector. The Content Validity Index (CVI) was used to analyze the validity of the individual content validity index (I-CVI) and the overall scale content validity index (S-CVI) for all sections. According to Dudovskiy (2016), acceptable scale content validity indexes should exceed 0.78 to deem it fit for further evaluation, i.e., pilot study. After a thorough assessment from five experts, all six questionnaire sections recorded a scale content validity index exceeding 0.78 , albeit a few item omissions deemed unnecessary, and too lengthy.
It was essential to specifically delineate the definition of environmental performance that we were seeking from the respondents. Then, based on previous relevant literature, respondents were asked to express their feedback on procedural and reward-based issues, including standard compliance augmentation, waste reduction, and systemization of production operations and gained advantages or disadvantages.

The final questionnaire contained six sections: 1) respondent's demographic information, 2) knowledge on ISO 14001, 3) knowledge on Carbon Footprint, 4) knowledge on Life Cycle Analysis, 5) knowledge on Material Flow Cost Accounting and 6) knowledge on Water Footprint. The questions were closeended and had multiple choice answers. An Environmental Compliance Audit Checklist requiring respondents to validate their compliance with environmental regulations was also enclosed at the end of the questionnaire. The regulation examples included an updated scheduled waste inventory, wastewater treatment plant, and permissible dark smoke limit for new facilities.

Succeeding the pre-test, the questionnaire was pilot tested on 15 ISO certified firms. Each interview lasted an hour, and the respondents were guided through the questionnaire on specific sections. They were encouraged to be open and provide details exemplifying their own experiences in handling ISO 14001 and Life Cycle Management tools to accompany their answers. The reliability of each scale for the 
items was assessed with Cronbach's alpha. A. H. Sharaai (personal communication, March 25, 2017) recommends the item values to be within the range of 0.65 to 0.95 to be deemed satisfactory. Fortunately, all 71 items recorded an overall value of 0.809 . Table 1 displays the Cronbach alpha values and the total number of items for all sections of the questionnaire.

Initially, a total of 200 questionnaires were mailed to ISO 14001 certified firms across the Klang Valley. Due to the scattered firm locations, a postal survey was deemed appropriate. Not only is the postal survey cost-effective, this ubiquitously utilized methodology also enables the gathering of substantial, representative data. The sample frame consisted of firm owners from a variety of sectors; the majority hailing from stationery and furniture manufacturing sectors. Information on registered firm owners was derived from the Federation of Malaysian Manufacturers directory online. We relied on the portal to identify and contact prospective firm owners. The information available included the firm's name, address, and contact number. This is a form of judgmental sampling, whereby the sample choice is purely at the discretion of the authors' judgement. There was a continuous follow-up procedure via telephone calls, emails, reminder letters and even personal visits to two respondents to ensure response. Care was taken to ensure that utilization of the information was conducted in a prudential manner that safeguarded the firm owners' privacy and rights. Table 2 displays the distribution of the 200 firms initially contacted according to sectors.

We recognized the possibility of survey response bias in which 'greener' and stringently compliant companies may be more prone to completing the questionnaire. In contrast, poorly performing certified companies may be averse to participate in the survey. Hence, the anonymity of the respondents was ensured to reduce reporting bias. Non-response bias was assessed

Table 2

Distribution of firms according to sector

\begin{tabular}{lc}
\hline Sector & Number of firms contacted \\
\hline Stationery & 75 \\
Furniture & 30 \\
Oil Refinery & 38 \\
Food Products & 44 \\
Electrical & 13 \\
\hline Total & 200 \\
\hline
\end{tabular}

Table 1

Reliability analysis for questionnaire sections

\begin{tabular}{lcc}
\hline Sections & Cronbach's alpha & Item numbers \\
\hline Demographic & 0.899 & 10 \\
Knowledge on ISO 14001 & 0.879 & 25 \\
Knowledge on Carbon Footprint & 0.733 & 11 \\
Knowledge on Life Cycle Analysis & 0.722 & 13 \\
Knowledge on Material Flow Cost Accounting & 0.791 & 10 \\
Knowledge on Water Footprint & 0.700 & 12 \\
\hline
\end{tabular}


by comparing questionnaires that were returned early with those returned late. Both responses were divided into two groups and eight items were randomly selected. T-tests were carried out on the responses. All t-tests resulted in no statistically significant differences among items tested.

It was salient that the respondents possessed a basic knowledge of environmental management techniques embedded within the ISO 14001 standard and Life Cycle Management tools at the firm level. Hence, a preliminary screening inquiry to determine the job qualification of the respondent was included. Results demonstrated a variety of employment positions and functions, i.e., environmental quality manager, project manager, senior manager, safety and training managers. The diversity of respondents validates the generalizability of the findings obtained, which is in accordance with the objectives of this study.

\section{RESULTS}

Out of 200 questionnaires sent, a total of 157 completed questionnaires were received back in good condition. The response rate (78.5\%) was deemed exceptionally good despite no incentive being enclosed together with the questionnaire.

\section{Descriptive Statistics}

The demographic variables described in Table 3 are the respondent's gender, age range, education level, and employment industry type.
Table 3

Descriptive statistics of demographic variables

\begin{tabular}{lcc}
\hline Variable & Frequency & $\begin{array}{c}\% \\
\text { (percentage) }\end{array}$ \\
\hline Gender & 82 & 52.22 \\
Male & 75 & 47.77 \\
Female & & \\
Age & 47 & 29.94 \\
$<23$ years old & 40 & 25.48 \\
24-30 years old & 35 & 22.29 \\
31-40 years old & 35 & 22.29 \\
$>41$ years old & & \\
Education level & 15 & 9.55 \\
High school & 20 & 12.74 \\
Foundation & 30 & 19.11 \\
Diploma & 47 & 29.94 \\
Degree & 45 & 28.56 \\
Postgraduate studies & & \\
Industry type & & 40.13 \\
Stationery Products & 63 & 10.19 \\
Furniture Products & 16 & 17.20 \\
Oil Refinery & 27 & 32.48 \\
Others (Food and & 51 & \\
Electrical) & & \\
\hline
\end{tabular}

Male respondents constituted the highest percentage (52.2) in comparison to female respondents. Majority were aged below 23 (29.94) and possessed a basic degree (29.94) in terms of education. Majority also worked in companies selling stationery (40.13).

\section{Analysis on Different Knowledge Levels between ISO 14001 and Life Cycle Management Tools}

One-Way ANOVA revealed significant differences between knowledge levels respondents had between ISO 14001 and Life Cycle Analysis, Material Flow Cost Accounting, Carbon Footprint and Water Footprint $[\mathrm{F}(3,624)=136.95, \mathrm{P}<.05]$. The 
Table 4

Test of between-subjects effects

\begin{tabular}{lccc}
\hline Source & Df. & F & Sig. \\
\hline Corrected Model & 3 & 136.953 & 0.000 \\
Intercept & 1 & 54210.193 & 0.000 \\
Life Cycle Management tools & 3 & 136.953 & 0.000 \\
\hline Error & & 624 & \\
Total & & 628 & \\
Corrected Total & 627 & \\
\hline
\end{tabular}

Table 5

Pairwise-comparison estimates of Life Cycle Management tools

\begin{tabular}{lcccccc}
\hline & & & & \multicolumn{3}{c}{$\begin{array}{c}\text { Knowledge of Life } \\
\text { Cycle Management } \\
\text { Tools Comparisons }\end{array}$} \\
\hline Group & $n$ & Mean & SD & $\begin{array}{c}\text { Carbon } \\
\text { Footprint }\end{array}$ & $\begin{array}{c}\text { Life Cycle } \\
\text { Assessment }\end{array}$ & $\begin{array}{c}\text { Material Flow } \\
\text { Cost Accounting }\end{array}$ \\
\hline Carbon Footprint & 157 & 92.20 & 9.289 & & \\
Life Cycle Assessment & 157 & 95.25 & 6.722 & 3.051 & \\
$\begin{array}{l}\text { Material Flow Cost } \\
\text { Accounting }\end{array}$ & 157 & 75.41 & 11.794 & $16.790^{*}$ & -19.841 & \\
Water Footprint & 157 & 91.11 & 9.609 & -1.089 & -4.140 & 15.701 \\
\hline
\end{tabular}

test of between-subject effect values is listed in Table 4, while the pairwise comparison estimates of each Life Cycle Management tool are listed in Table 5.

Life Cycle Analysis knowledge recorded the highest mean, while Material Flow Cost Accounting the lowest. After the control of the type 1 error using the Bonferroni method, the Carbon FootprintMateria Flow Cost Accounting comparison recorded a significant mean difference value of 16.79 ( $<$ <.05). Also, the Life Cycle Analysis-Water Footprint pair displayed a significant difference with the mean value of $4.14(\mathrm{p}<.05)$, followed by the Life Cycle Analysis-Carbon Footprint pair (mean difference $=3.05, \mathrm{p}<.05$ ). However, there was no significant difference between
Carbon Footprint and Water Footprint (mean difference $=1.089, \mathrm{p}>.05$ ). There was only a small mean difference between these two tools, i.e., Carbon Footprint ( $\min 92.20$ ) and Water Footprint $(\min =91.12)$.

\section{Analysis of Factors Contributing to Environmental Performance}

Results show that three of the five independent variables significantly contributed toward the environmental performance of all 157 ISO 14001 certified firms, i.e., Carbon Footprint $(\beta=.330$, $p$ $<.05)$, ISO $14001(\beta=.309, \mathrm{p}<.05)$ and Material Flow Cost Accounting $(\beta=.230, p$ $<.05)$. The multiple linear regression results are displayed in Table 6 as follows. 
Table 6

Regression estimates of variable coefficients

\begin{tabular}{|c|c|c|c|c|c|c|}
\hline \multicolumn{2}{|c|}{ Model } & \multirow{2}{*}{$\frac{B}{62.474}$} & \multirow{2}{*}{$\begin{array}{l}S E B \\
5.530\end{array}$} & \multirow[t]{2}{*}{$\beta$} & \multirow{2}{*}{$\frac{t}{11.298}$} & \multirow{2}{*}{$\begin{array}{c}\frac{p}{0.000} \\
\end{array}$} \\
\hline 1 & (Constant) & & & & & \\
\hline & Carbon Footprint & 0.314 & 0.059 & 0.398 & 5.276 & 0.000 \\
\hline \multirow[t]{3}{*}{2} & (Constant & 51.410 & 5.616 & & 9.155 & 0.000 \\
\hline & Carbon Footprint & 0.320 & 0.055 & 0.406 & 5.783 & 0.000 \\
\hline & ISO 14001 & 0.153 & 0.031 & 0.344 & 4.908 & 0.000 \\
\hline \multirow[t]{4}{*}{3} & (Constant) & 47.602 & 5.584 & & 8.524 & 0.000 \\
\hline & Carbon Footprint & 0.260 & 0.057 & 0.330 & 4.564 & 0.000 \\
\hline & ISO 14001 & 0.137 & 0.031 & 0.309 & 4.470 & 0.000 \\
\hline & Material Flow Cost Accounting & 0.139 & 0.044 & 0.230 & 3.155 & 0.000 \\
\hline
\end{tabular}

Note. Dependent variable: Environmental Performance

\section{DISCUSSION}

\section{Identifying the Different Knowledge Levels between ISO 14001 and Life Cycle Management Tools}

The different levels of knowledge are related to the duration of exposure and advertisement by environmental bodies. The role of information dissemination has been emphasized by various researchers as a critical medium for comprehension and behavioral formation among users of technology (Kjaer et al., 2018; Nero et al., 2016; Suryanto et al., 2018). Life Cycle Assessment has existed for over a decade and most environmental management standard users have been exposed to the standardized techniques and methodology to access potential impacts of a product over its life cycle stages. Thus, a high knowledge score on Life Cycle Assessment is expected and reasonable.

In contrast to preconceived notions, Carbon Footprint and Water Footprint recorded high mean scores. This is attributed to the fact that these footprints consider the impact perspective of only one observable resource respectively. Concisely, both focus on a specific category of emission, consider the quantification of natural resources either as positive exploitation or waste generation (both being life cycle stages) and are limited to certain processes (Giannarakis et al., 2017; Lee et al., 2016; Safie et al., 2018) Lastly, these two resources are inherently linked, whereby a large supply of energy (carbon) is generated for supply, treatment and usage of freshwater in product manufacturing (Hoekstra, 2017). Hence knowledge dissemination on calculation and treatment is focused, interlinked and not overgeneralized. Assessments have been duly promoted by the Malaysian SIRIM organization under the banner of product footprint certification (Abdullah et al., 2017; H. K. Salim et al., 2018). The officials are responsible for convincing ISO 14001 certified firm owners to utilize energy sources efficiently and reduce energy and water consumption. It should be noted that these assessments have been implemented 
since 2005; hence, governmental officials have had ample time to disseminate the knowledge via workshops and seminars.

The low score recorded for Material Flow Cost Accounting was expected, as it is a relatively new monetary tool aimed at improving environmental and economic performance simultaneously. Most respondents were unfamiliar with the economic terms contained within the questions. Another major hurdle is the pronounced familiarity of respondents with conventional cost accounting for financial management. Material Flow Cost Accounting differs significantly from conventional cost accounting. This is perceived in how both methods segregate production outputs into complete products and effluents (El-Mousawi \& Charbaji, 2016). Conventional cost accounting lists total output as a complete product and assigns effluent waste as an overhead cost. On the other hand, Material Flow Cost Accounting not only divide outputs into finished product and waste, but it also gathers flow output into an assigned quantity center (Marota et al., 2017; K. M. Salim et al., 2018). Here, the data is examined in order to pinpoint which parts flow to the products, and which parts are merely losses. Hence the latter is a more systematic method to delineate material loss.

\section{Factors Contributing to Environmental Performance}

As predicted, knowledge of ISO 14001 proved to be positively significant in influencing environmental performance.
This was demonstrated through the respondents' ability to answer most questions accurately regarding clauses on ISO 14001, Plan-Do-Check-Act (PDCA) guidelines and origin information. ISO 14001 certification guidelines, motivations, and benefits are readily available online and free for perusal (Nero et al., 2016; Mei et al., 2016). Moreover, the standard is extensively promoted via the Department of Standards (Department of Standards Malaysia, 2017). Periodical seminars and workshops are often organized by the organization. Several respondents also highlighted the decentralized participatory-based approach conducted by officers emphasized an open, top-down approach.

Carbon Footprint was also a significantly positive determinant. Knowledge of Carbon Footprint allows the lessening of carbon emissions that are directly or indirectly generated by manufacturing activities over the lifespan of a product (Fernando \& Hor, 2017; Giannarakis et al., 2017). Respondents were duly aware of the quantification of direct emissions (e.g., heating, manufacturing, transport, on site incinerators), controlled indirect emissions (purchased electrical or heat machines) and non-controlled indirect emissions (raw material commutes, labor travels) based on their questionnaire answers. Questions on emission control benefits also revealed that majority of participants understood that performance of their firms would improve via reduced energy costs, and amelioration of the firms' surrounding environmental health. 
Unexpectedly, Material Flow Cost Accounting was deemed to be a significant determinant. This is counterintuitive to the previous finding on knowledge levels where it was the lowest amongst firm owners. Fundamentally, it is a monetary tool whereby owners can implicitly recognize material and energy trends in business operations and perceive how these trends relate to expenditure (Marota et al., 2017; Rieckhof \& Guenther, 2018). It is postulated that the positive appraisal of Material Flow Cost Accounting as an environmental performance booster is correlated with the utility maximization paradigm, i.e., an individual is assumed to be rational and choose a practice or methodology that optimizes his utility options. In this context, firm owners recognize its potential to boost both environmental and economic performance (K. M. Salim et al., 2018; Turner et al., 2016). Being businessoriented individuals, profitability is a pivotal decision-making determinant (ElMousawi \& Charbaji, 2016; Testa et al., 2016). This paradigm can be conceptualized as a livelihood consideration. While the knowledge and awareness on Material Flow Cost Accounting were demonstrated as low, the interest on it as a significant environmental performance investment could be a steppingstone in increasing its dissemination knowledge by experts.

Contrasting results were observed on the statistical significance of Life Cycle Assessment and Water Footprint knowledge. Both were not significant in influencing environmental performance. One probable factor is that firm owners generally regard the unrevised ISO 14001 version as sufficient to address environmental issues and perceive the inclusion of Life Cycle Thinking and Life Cycle Assessment tools as unnecessary and cumbersome (Pfister et al., 2017). This may explain the low number of firms reverting to the ISO 14001: 2015 (H. K. Salim et al., 2018). On the other hand, firm owners may also perceive Life Cycle Assessment and Water Footprint as complex and challenging to comprehend. Components that need to be studied and inventoried include functions of the product system, functional units, input allocation, impact assessment categories and their relevant methodologies (Pawel et al., 2016; Weidema et al., 2018). Moreover, these tools require constant data update on a variety of inputs in settings that may experience constant change (Pfister et al., 2017). Concisely, both Life Cycle Assessment and Water Footprint are complex inventory tools that involve numerous technical choices and assumptions (Chatzisymeon et al., 2017; Pfister et al., 2017). Examples include Water Footprint reduction benchmarks and reporting.

Another is the limitation of data required to calculate Water Footprint. If a firm owner is not familiar with varying impact categories, impact assessment steps, data calculation involving multiple products and unit processes, and how to interpret the results obtained, then the Life Cycle Assessment is perceived to be too technical for the common layman and represent an unnecessary trade-off in relation to increasing environmental performance (Chatzisymeon et al., 2017; Testa et al., 
2016). The calculation of Water Footprint in Malaysia nationally is limited at both state and city levels (Lee et al., 2016). This is unfortunate as information obtained on these levels will be useful in guiding development planning. The fact that there is no commonly accepted method for Water Footprint calculations poses a challenge. Another is the limitation of data required to calculate Water Footprint.

\section{CONCLUSION}

Relevant environmental education pertaining to Life Cycle Thinking and Life Cycle Management tools for all levels in a firm is necessary for effective corporate environmental management (Ingrao et al., 2018; Murmura et al., 2018; Turner et al., 2016). Themes revolving around environmental policy, environmental impacts and economic planning pertaining to input flow analysis should be addressed and implemented (Lee et al., 2017; Suryanto et al., 2018). Insufficient training and knowledge dissemination by ISO 14001 and Life Cycle Management experts will result in the unwillingness of both management officials and employees to be environmentally proactive (Ejdys et al., 2016; Oliveira et al., 2016). A business culture that emphasizes a top-down approach and decentralized form of education can help develop positive green perception and value, which are necessary to create a sustainable business model (Carvalho et al., 2016; Oliveira et al., 2016).

Future research can augment these findings by appraising the perceptions and surmises amongst a wider number of local stakeholders: notably, small and medium retailers that have been certified. In addition to increasing the sample size, alternate theoretical perspectives focusing on the influence of internal and external firm characteristics should be included. Spatial and temporal determinants should be evaluated to capture their influence on the motivations and barriers to environmental management standards adoption. Since environmental performance was found to vary across the different knowledge levels as evidenced by the recorded scores, the causes in knowledge variation across the ISO certified sector should be explored further. Other environmental assessment indicators, i.e., risk assessment, cost-benefit analysis, eco-labeling, Social Life Cycle Assessment should be included as well.

\section{ACKNOWLEDGEMENT}

The authors would like to express their gratitude to the 157 ISO 14001 certified firms for participating voluntarily in the survey, enabling the completion of this research. The authors would also like to thank the Faculty of Forestry and Environment, Universiti Putra Malaysia for availing us the opportunity to gather the required information for this study.

\section{REFERENCES}

Abdullah, H., Jali, M. R. M., \& Ibrahim, F. W. (2017). The current state of Malaysia's journey towards a green economy: The perceptions of the companies on environmental efficiency and sustainability. International Journal of Energy Economics and Policy, 7(1), 253-258. 
Ahmad, M. S., Bazmi, A. A., Bhutto, A. W., Shahzadi, K., \& Bukhari, N. (2016). Students' responses to improve environmental sustainability through recycling: Quantitatively improving qualitative model. Applied Research in Quality of Life, 11(1), 253-270. https://doi.org/10.1007/s11482014-9366-7

Aivazidou, E., Tsolakis, N., Iakovou, E., \& Vlachos, D. (2016). The emerging role of water footprint in supply chain management: A critical literature synthesis and a hierarchical decision-making framework. Journal of Cleaner Production, 137, 1018-1037. https://doi.org/10.1016/j. jclepro.2016.07.210

Anđić, D., \& Vorkapić, S. T. (2017). Teacher education for sustainability: The awareness and responsibility for sustainability problems. Journal of Teacher Education for Sustainability, 19(2), 121-137. https://doi.org/10.10.1515/jtes2017-0018

Boiral, O., Guillaumie, L., Heras-Saizarbitoria, I., \& Tene, C. V. T. (2018). Adoption and outcomes of ISO 14001: A systematic review. International Journal of Management Reviews, 20(2), 411432. https://doi.org/10.1111/ijmr.12139

Carvalho, M., de Santana Freire, R., \& de Brito, A. M. V. G. (2016). Promotion of sustainability by quantifying and reducing the carbon footprint: New practices for organizations. In Energy, transportation and global warming (pp. 61-72). Springer. https://doi.org/10.1007/978-3-31930127-3 6

Chatzisymeon, E., Foteinis, S., \& Borthwick, A. (2017). Life Cycle Assessment of the environmental performance of conventional and organic methods of open field pepper cultivation system. The International Journal of Life Cycle Assessment, 22(6), 896-908. https:// doi.org/10.10.1007/s11367-016-1204-8

Daddi, T., Nucci, B., \& Iraldo, F. (2017). Using Life Cycle Assessment (LCA) to measure the environmental benefits of industrial symbiosis in an industrial cluster of SMEs. Journal of Cleaner Production, 147, 157-164. https://doi. org/10.1016/j.jclepro.2017.01.090

Department of Standards Malaysia. (2017). JSM portal: Popular Standards: MS ISO 14001: 2015 - Environmental Management Systems. https:// www.jsm.gov.my/ms-iso-14001

Dudovskiy, J. (2016). Purposive sampling. https:// research-methodology.net/sampling-in-primarydata-collection/purposive-sampling

Ejdys, J., Matuszak-Flejszman, A., Szymanski, M., Ustinovichius, L., Shevchenko, G., \& LulewiczSas, A. (2016). Crucial factors for improving the ISO 14001 environmental management system. Journal of Business Economics and Management, 17(1), 52-73. https://doi.org/10. 10.3846/16111699.2015.1065905

El-Mousawi, H. Y., \& Charbaji, A. (2016). Attitude of Lebanese managers towards ISO 14001-Environmental Management System and ISO 14051-Material Flow Cost Accounting. International Journal of Management, 7(2), 224-235.

Fernando, Y., \& Hor, W. L. (2017). Impacts of energy management practices on energy efficiency and carbon emissions reduction: A survey of Malaysian manufacturing firms. Resources, Conservation and Recycling, 126, 62-73. https:// doi.org/10.1016/j.resconrec.2017.07.023

Fernando, Y., \& Saththasivam, G. (2017). Green supply chain agility in EMS ISO 14001 manufacturing firms: Empirical justification of social and environmental performance as an organisational outcome. International Journal of Procurement Management, 10(1), 51-69. https:// doi.org/10.10.1504/IJPM.2017.10000826

Fonseca, L., \& Domingues, J. (2018). Exploratory research of ISO 14001: 2015 transition among Portuguese organizations. Sustainability, 10(3), 781. https://doi.org/10.10.3390/su10030781 
Giama, E., \& Papadopoulos, A. M. (2018). Carbon footprint analysis as a tool for energy and environmental management in small and medium-sized enterprises. International Journal of Sustainable Energy, 37(1), 21-29. https://doi. org/10.10.1080/14786451.2016.1263198

Giannarakis, G., Zafeiriou, E., \& Sariannidis, N. (2017). The impact of carbon performance on climate change disclosure. Business Strategy and the Environment, 26(8), 1078-1094. https://doi. org/10.1007/s11142-021-09611-x

Hoekstra, A. Y. (2017). Water footprint assessment: Evolvement of a new research field. Water Resources Management, 31(10), 3061-3081. https://doi.org/10.1007/s11269-017-1618-5

Ingrao, C., Messineo, A., Beltramo, R., Yigitcanlar, T., \& Ioppolo, G. (2018). How can life cycle thinking support sustainability of buildings? Investigating life cycle assessment applications for energy efficiency and environmental performance. Journal of Cleaner Production, 201, 556-569. https://doi.org/10.1016/j.jclepro.2018.08.080

International Organization for Standardization. (2017). ISO 14001 Environmental Management. https://www.iso.org/iso-14001-environmentalmanagement.html

Jolliet, O., Antón, A., Boulay, A. M., Cherubini, F., Fantke, P., Levasseur, A. \& Pfister, S. (2018). Global guidance on environmental life cycle impact assessment indicators: Impacts of climate change, fine particulate matter formation, water consumption and land use. The International Journal of Life Cycle Assessment, 23(11), 2189-2207. https://doi.org/10.1007/s11367018-1443-y

Kjaer, L. L., Pigosso, D. C., McAloone, T. C., \& Birkved, M. (2018). Guidelines for evaluating the environmental performance of Product/ Service-Systems through life cycle assessment. Journal of Cleaner Production, 190, 666-678.
Lee, K. E., Mokhtar, M., Hanafiah, M. M., Halim, A. A., \& Badusah, J. (2016). Rainwater harvesting as an alternative water resource in Malaysia: Potential, policies and development. Journal of Cleaner Production, 126, 218-222.

Lee, S. M., Noh, Y., Choi, D., \& Rha, J. S. (2017). Environmental policy performances for sustainable development: From the perspective of iso 14001 certification. Corporate Social Responsibility and Environmental Management, 24(2), 108-120.

Marota, R., Ritchi, H., Khasanah, U., \& Abadi, R. F. (2017). Material flow cost accounting approach for sustainable supply chain management system. International Journal of Supply Chain Management, 6(2), 33-37.

Marton, F., \& Booth, S. A. (1997). Learning and awareness. Psychology Press.

Mei, N. S., Wai, C. W., \& Ahamad, R. (2016). Environmental awareness and behaviour index for Malaysia. Procedia-Social and Behavioral Sciences, 222, 668-675. https://doi.org/10.1016/j. sbspro.2016.05.223

Murmura, F., Liberatore, L., Bravi, L., \& Casolani, N. (2018). Evaluation of Italian companies' perception about ISO 14001 and eco management and audit scheme III: Motivations, benefits and barriers. Journal of Cleaner Production, 174, 691-700.

Nero, M., Corina, J., \& Mariam, R. (2016). Impediments of Environment Management System (EMS) implementation in Malaysian local authorities - A preliminary finding. SHS Web of Conferences, 3, 25-26. https://doi. org/10.1051/shsconf/20173405001

Oliveira, J. A., Oliveira, O. J., Ometto, A. R., Ferraudo, A. S., \& Salgado, M. H. (2016). Environmental management system ISO 14001 factors for promoting the adoption of Cleaner Production practices. Journal of Cleaner Production, 133, 1384-1394. 
Pawel, F., Przemyslaw, K., Anna, L., Jaroslaw, S., \& Andrzej, Z. (2016). An environmental life cycle assessment of forklift operation: A well-to-wheel analysis. Journal of Life Cycle Assessment, 21, 1438-1451. https://doi.org/10.1007/s11367016-1104-y

Pfister, S., Boulay, A. M., Berger, M., Hadjikakou, M., Motoshita, M., Hess, T., \& Manzardo, A. (2017). Understanding the LCA and ISO water footprint: A response to Hoekstra (2016) "A critique on the water-scarcity weighted water footprint in LCA". Ecological Indicators, 72, 352-359. https://doi. org/10.1016/j.ecolind.2016.07.051

Ridoutt, B. G., Pfister, S., Manzardo, A., Bare, J., Boulay, A. M., Cherubini, F., \& Jolliet, O. (2016). Area of concern: A new paradigm in life cycle assessment for the development of footprint metrics. The International Journal of Life Cycle Assessment, 21(2), 276-280. https:// doi.org/10.10.1007/s11367-015-1011-7

Rieckhof, R., \& Guenther, E. (2018). Integrating life cycle assessment and material flow cost accounting to account for resource productivity and economic-environmental performance. The International Journal of Life Cycle Assessment, 23(7), 1491-1506.

Safie, N. A., Malek, M. A., \& Noor, Z. Z. (2018). Water footprint assessment and Water-Energy-Food Nexus for domestic and institutional sectors in Klang Valley, Malaysia: A review. International Journal of Engineering and Technology (UAE), 7(4), 244-247.

Salim, H. K., Padfield, R., Hansen, S. B., Mohamad, S. E., Yuzir, A., Syayuti, K., \& Papargyropoulou, E. (2018). Global trends in environmental management system and ISO 14001 research. Journal of Cleaner Production, 170, 645-653.

Salim, K. M., Amir, A. M., \& Sulaiman, M. (2018). Material flow cost accounting, perceived ecological environmental uncertainty, supplier integration and business performance: A study of manufacturing sector in Malaysia. Asian Journal of Accounting and Governance, 8, 107-122. https://doi.org/10.17576/AJAG-2017-08SI-10

Sammalisto, K., Sundström, A., Von Haartman, R., Holm, T., \& Yao, Z. (2016). Learning about sustainability - What influences students' self-perceived sustainability actions after undergraduate education? Sustainability, 8(6), 510. https://doi.org/10.3390/su8060510

Suryanto, T., Haseeb, M., \& Hartani, N. H. (2018). The correlates of developing green supply chain management practices: Firms level analysis in Malaysia. International Journal of Supply Chain Management, 7(5), 316-324.

Svensson, G., Ferro, C., Høgevold, N., Padin, C., Varela, J. C. S., \& Sarstedt, M. (2018). Framing the triple bottom line approach: Direct and mediation effects between economic, social and environmental elements. Journal of Cleaner Production, 197(Part 1), 972-991. https://doi. org/10.1016/j.jclepro.2018.06.226

Testa, F., Nucci, B., Tessitore, S., Iraldo, F., \& Daddi, T. (2016). Perceptions on LCA implementation: Evidence from a survey on adopters and nonadopters in Italy. The International Journal of Life Cycle Assessment, 21(10), 1501-1513. https://doi.org/10.1007/s11367-016-1106-9

Turner, D. A., Williams, I. D., \& Kemp, S. (2016). Combined material flow analysis and life cycle assessment as a support tool for solid waste management decision making. Journal of Cleaner Production, 129, 234-248. https://doi. org/10.1016/j.jclepro.2016.04.077

Weidema, B. P., Pizzol, M., Schmidt, J., \& Thoma, G. (2018). Attributional or consequential Life Cycle Assessment: A matter of social responsibility. Journal of Cleaner Production, 174, 305-314. https://doi.org/10.1016/j.jclepro.2017.10.340 
